\title{
Primary Care of Overweight Children: The Importance of Parent Weight and Attitudes about Overweight: A MetroNet Study
}

\author{
Rosalie F. Young, PhD, MA, Kendra L. Schwartz, MD, MSPH, Joseph C. Monsur, BS, \\ Patricia West, PhD, and Anne Victoria Neale, PhD, MPH
}

Purpose: The purpose of this study was to identify the association of parents' weight and attitude about their child's weight with the child's body mass index (BMI) status.

Design: Cross-sectional, clinic-based study in a practice-based research network.

Methods: One hundred seventy-one parents or adults accompanying children aged 5 to 17 years to a primary care visit in $\mathbf{4}$ family medicine centers completed a questionnaire. Parent/adult overweight status and attitudes were compared with child overweight status.

Results: Forty-eight percent of children were overweight or obese (BMI $\geq$ the 85 th percentile) as were $56 \%$ of mothers and $77 \%$ of fathers $\left(B M I \geq 25 \mathrm{~kg} / \mathrm{m}^{2}\right)$. Child and parent overweight were significantly associated, as were mother overweight and beliefs about child overweight status. Children aged 5 to 13 years were more likely to be overweight than those aged $\geq 14$ years.

Conclusions: Parents of overweight children are often overweight and many do not recognize that their children are overweight. Suggestions are made for primary care physicians to engage parents of overweight children in family weight control efforts. (J Am Board Fam Med 2008;21:361-363.)

In 2003 to $2004,17.1 \%$ of US children and adolescents were overweight and $32.2 \%$ of adults were obese. ${ }^{1}$ The epidemic of childhood obesity and overweight is challenging primary care physicians to champion the changes needed to alter their patients' eating, exercise, and lifestyle choices. ${ }^{2}$ Family patterns of obesity and the parental influence on child weight that begins at conception are well recognized. ${ }^{3}$ We hypothesized that child obesity has a family context and that parents of overweight children may not accurately recognize the child's overweight status.

This article was externally peer reviewed.

Submitted 28 February 2008; revised 21 March 2008; accepted 26 March 2008.

From the Department of Family Medicine and Public Health Sciences, Wayne State University School of Medicine, Detroit, Michigan (RFY, KLS, JCM, AVN); and Family Medicine Residency Program, St. John Hospital, Detroit, Michigan (PW).

Funding: Supported in part by an Academic Administrative Units award from the DHHS Health Resources Services Administration Bureau of Health Professions.

Conflict of interest: none declared.

Corresponding author: Rosalie Young, PhD, Department of Family Medicine and Public Health Sciences, Wayne State University School of Medicine, 101 Alexandrine, Detroit, MI 48201 (E-mail: ryoung@med.wayne.edu).

\section{Methods}

\section{Design and Subjects}

Using a cross-sectional survey study design, parents or adults accompanying a child aged 5 to 17 years to a primary care visit were asked to complete a study questionnaire. One hundred seventy-one adults were recruited from 1 of 4 family medicine centers that are members of the MetroNet practice-based research network. Almost all the adult respondents (92.4\%) were the parents of the children that they accompanied; $5.3 \%$ were not parents; and for $2.3 \%$, the relationship to the child was missing (hereafter we refer to the adult respondents as "parents"). These parents provided all study data including the child's weight status, the weight status of both father and mother, and the parent's belief about the child's overweight status.

\section{Data Analysis}

Overweight for children was defined as the 85 th percentile body mass index (BMI) for age; for adults, overweight was defined as $\mathrm{BMI} \geq 25 \mathrm{~kg} / \mathrm{m}^{2}$. $\chi^{2}$ tests were used to examine the associations of child overweight status with child demographic 


\begin{tabular}{|c|c|c|c|c|}
\hline & \multirow{2}{*}{$\begin{array}{c}\text { All Subjects } \\
(\mathrm{n}=171) \\
(\%)\end{array}$} & \multicolumn{2}{|c|}{ Child BMI $\geq 85 \%$ percentile* } & \multirow[b]{2}{*}{$P$} \\
\hline & & $\begin{array}{c}\text { Yes }(\mathrm{n}=67) \\
(\%)\end{array}$ & $\begin{array}{c}\text { No }(\mathrm{n}=74) \\
(\%)\end{array}$ & \\
\hline Child's age & & & & 0.04 \\
\hline 5 to 10 years & $63(37.7)$ & $25(37.3)$ & $20(27.0)$ & \\
\hline 11 to 13 years & $40(24.0)$ & $21(31.3)$ & $15(20.3)$ & \\
\hline 14 to 17 years & $64(38.3)$ & $21(31.3)$ & $39(52.7)$ & \\
\hline Child's sex & & & & 0.93 \\
\hline Male & $81(48.5)$ & $33(49.3)$ & $33(49.3)$ & \\
\hline Female & $86(51.5)$ & $34(50.7)$ & $37(50.0)$ & \\
\hline Child's race & & & & 0.32 \\
\hline Black & $53(31.9)$ & $26(38.8)$ & $21(28.8)$ & \\
\hline White & $91(54.8)$ & $31(46.3)$ & $43(58.9)$ & \\
\hline Other & $22(13.3)$ & $10(14.9)$ & $9(12.3)$ & \\
\hline Mother overweight ${ }^{\dagger}$ & & & & 0.02 \\
\hline Yes & $86(55.5)$ & $42(66.7)$ & $32(46.4)$ & \\
\hline No & $69(44.5)$ & $21(33.3)$ & $37(53.6)$ & \\
\hline Father overweight ${ }^{\dagger}$ & & & & 0.06 \\
\hline Yes & $107(77.0)$ & $46(86.8)$ & $48(72.7)$ & \\
\hline No & $32(23.0)$ & $7(13.2)$ & $18(27.3)$ & \\
\hline Do you think child weighs more than he/she should? & & & & 0.01 \\
\hline Yes & $33(20.0)$ & $28(42.4)$ & $1(1.4)$ & \\
\hline No & $132(80.0)$ & $38(57.6)$ & $72(98.6)$ & \\
\hline
\end{tabular}

*BMI $\geq 85$ percentile: at-risk for overweight and overweight.

${ }^{\dagger}$ Parent overweight defined as $\mathrm{BMI} \geq 25 \mathrm{~kg} / \mathrm{m}^{2}$.

variables, plus parent weight status and parent attitude about the child's weight status.

\section{Results}

The mean age of the children accompanying the parent respondents was 11.6 years and $51.5 \%$ of the children were female. Parental reports of the child's race were as follows: $54.8 \%$ white, $31.9 \%$ black, and $13.3 \%$ other (see Table 1).

Data on the child's weight status was obtained from 141 of the 171 parent respondents. Based on parents' responses, we calculated 67 children with a $\mathrm{BMI} \geq 85$ th percentile. Younger age was associated with overweight status, with children ages 5 to 13 years more likely to be overweight than those 14 years or older. Parents reported that $55.5 \%$ of mothers were overweight; maternal overweight was associated with child overweight $(P=.02)$. Respondents were less likely to provide weight status information for fathers ( $\mathrm{n}=32$ missing); however, for the data reported, $77.0 \%(107 / 139)$ of fathers were overweight. Father overweight status was also associated with child overweight $(P=.06)$.
We examined the association of child weight status with parental perception of the child's weight. Almost all (72/73 or $98.6 \%)$ parents with a child of normal weight indicated their child was not overweight. However only 42.4\% (28/66) of parents with an overweight child indicated their child was overweight $(P<.001)$.

We hypothesized that the overweight parents would be more likely to indicate their overweight child was not overweight. We had insufficient numbers for a valid $\chi^{2}$ test that combined both parents, which we believe resulted from limited variance with the fathers' weight status variable. Among the 42 overweight mothers with overweight children, $20(47.6 \%)$ did not think the child was overweight whereas $22(52.4 \%)$ thought that the overweight child (BMI $>85 \%)$ was indeed overweight $(P=$ $.04)$.

\section{Discussion}

The parents in our study tended to say that their overweight child was not overweight, with slightly less than half of all parents correctly recognizing their 
child's overweight status. In addition, child overweight was associated with parental overweight. These findings highlight the family context of weight problems, especially among younger children, and suggest that child obesity interventions should optimally focus on physician-parent partnerships. ${ }^{4}$

Physicians might first advise parents of overweight children about the risks of obesity-related problems that can harm the child's health. Then they can act as change agents ${ }^{2}$ and offer familybased interventions that are designed for primary care providers ${ }^{5}$ and which include health education and efforts to change misunderstandings of healthy weight for children.

In addition, resources are recommended for physicians to identify those parents ready to make changes for overweight children and to identify families that are likely to benefit from physician-led interventions. ${ }^{6}$ Other suggestions are to consider using published guidelines for family interventions as reviewed by Snethen et $\mathrm{al}^{7}$ or proposed by O'Brien et $\mathrm{al}^{8}$ and Epstein. ${ }^{9}$ Among families where the child is overweight and particularly among families where both parents and children are overweight, the family unit is the elemental focal point for reducing the prevalence of childhood obesity and encouraging healthy eating. This can be a most important role for primary care physicians who seek to be change agents. ${ }^{2}$

\section{References}

1. Ogden CL, Carroll MD, Curtin LR, et al. Prevalence of overweight and obesity in the United States, 1999-2004. JAMA 2006;295:1549-55.

2. Lavizzo-Mourey R. Childhood obesity: What it means for physicians. JAMA 2007;298:920-2.

3. Savage J, Fisher J, Birch L. Parental influence on eating behavior: Conception to adolescence. J Law Med Ethnics 2007;35:22-34.

4. Wald ER, Ewing L, Cluss P, et al. Establishing a family-based intervention for overweight children in pediatric practice. Ann Fam Med 2005;3(supp 2): S45-7.

5. Meizi H, Evans A. Are parents aware that their children are overweight or obese? Do they care? Can Fam Physician 2007;53:1493-9.

6. Rhee KE, De Lago CW, Arscott-Mills T, et al. Factors associated with parental readiness to make changes for overweight children. Pediatrics 2005; 116:e94-101.

7. Snethen JA, Broome ME, Cashin ES. Effective weight loss for overweight children: A meta-analysis of intervention studies. J Pediatr Nurs 2006;21:4556.

8. O'Brien SH, Holubkov R, Reis EC. Identification, evaluation, and management of obesity in an academic primary center. Pediatrics 2004;114:e154-9.

9. Epstein LH. Family-based behavioural intervention for obese children. Int J Obes Relat Metabo Disord 1996;20(suppl 1):S14-21. 